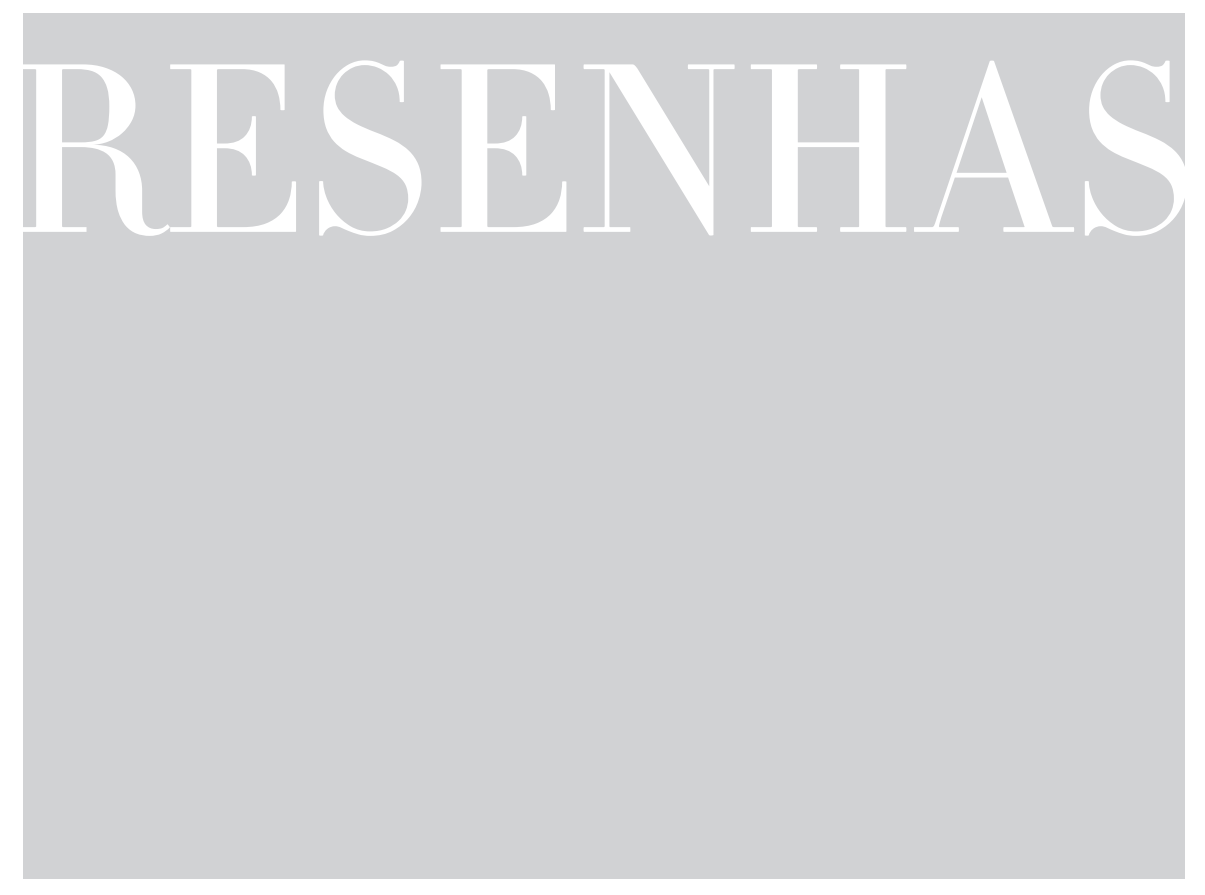

\title{
POLÍTICAS PÚBLICAS E AUTONOMIA FEMININA: UMA RELAÇÃO DE CONTRADIÇÕES
}

https://doi.org/10.1590/198053145317

\author{
VERIDIANA PARAHYBA CAMPOS'
}

GEORGES, Isabel; SANTOS, Yumi Garcia dos. As novas politicas

públicas sociais na saúde e na assistência: produção local do serviço

e relações de gênero. Belo Horizonte: Fino Traço, 2016.

O Brasil pode ser considerado um 'laboratório' de 'novas' políticas sociais. Só que essas “novas” políticas trazem em si uma contradição interna: ao mesmo tempo que expressam o reconhecimento das reinvindicações populares, fruto das lutas democráticas, também carregam as marcas do neoliberalismo capitalista que prevê a diminuição dos investimentos sociais. A ciência dessa verdadeira condição de "puxa-encolhe”, observada pelas sociólogas Isabel Georges e Yumi dos Santos na obra aqui resenhada (2016), faz dela um estudo diferenciado e rigoroso sobre como têm se desenvolvido as bases epistêmicas e o funcionamento cotidiano de políticas públicas brasileiras sedimentadas tais como o Programa Saúde da Família (PSF), por exemplo.

Entremeada na análise de algumas das principais políticas públi-

cas brasileiras, as autoras nos brindam com uma rica discussão de gênero, que complexifica o papel das mulheres, tanto como usuárias de tais políticas quanto como as operadoras que as colocam em prática na função de agentes comunitárias de saúde. Observando com especial interesse o 
caso brasileiro, mas passeando por outros lugares, notadamente Europa e América Latina, o trabalho traz um olhar assumidamente preocupado com a influência daquilo que a teoria feminista nomeia de papéis de gênero na formação, desenvolvimento e implementação dessas políticas. Entendendo que tal mirada é absolutamente necessária, mas nem sempre utilizada com a dose certa de precisão e de crítica, uma vez que encontramos isso no livro, seu resultado torna-se especial.

Com isso em mente, a partir de pesquisa de campo efetuada na zona leste de São Paulo, em Cidade Tiradentes, entre os anos de 2010 e 2012, as autoras se propuseram a estudar profissionais e usuários da Estratégia Saúde Família (ESF), serviço do governo federal tradicionalmente chamado de Programa de Saúde da Família (PSF) e do Programa Ação Família (PAF), programa municipal paulista, também atuante em Cidade Tiradentes e em Itaquera. Pesquisaram vida e trabalho dos e das agentes comunitários/as de saúde e da comunidade assistida por eles/as. A metodologia para recolhimento das informações envolveu etnografia e observação participante, além de mais de cem entrevistas feitas tanto nos postos de atendimento como nas residências das pessoas.

O livro está dividido em três partes: 1) A emergência das "novas" políticas sociais brasileiras no contexto internacional, nacional e local; 2) Mercantilização da pobreza e as formas de atuação das mulheres; e 3) Análise das trajetórias. Revezando-se na escrita dos artigos nas três partes, essa subdivisão demonstra de antemão qual a perspectiva de entendimento que guia as autoras na compreensão do problema: uma estratégia heurística dialética do abstrato para o concreto.

Esses agentes comunitários de saúde (ACS) e agentes de proteção social (APS) são trabalhadores e trabalhadoras que põem em prática, dentro mesmo da comunidade, iniciativas de Estado, tentando legitimá-las e fazê-las funcionar da melhor forma possível. Nessa função, há algumas peculiaridades que motivaram as pesquisadoras a estudá-las: são sempre pessoas da própria comunidade com a finalidade de atender a população de seus bairros e redondezas "numa perspectiva de proximidade e continuidade” (p. 20). Na fronteira entre o emprego público e privado, não são estatutários. De origem humilde e com pouca ou nenhuma formação profissional prévia, na grande maioria mulheres, são entendidas pelas pesquisadoras como as articuladoras entre as esferas do Estado e a população assistida.

Pensando na perspectiva dos Estudos do Trabalho, trata-se de um subemprego, que serve de oportunidade de trabalho, de acúmulo de conhecimentos e de status na comunidade para mulheres cuja situação social é vulnerável ou cujas oportunidades tendem a ser limitadas. Além disso, antes de serem contratadas como agentes, essas mulheres já eram (e permanecem) usuárias das tais políticas, conhecem as pessoas da vizinhança, e têm laços com o lugar e com a população local, pois isso é 
condição sine qua non para o exercício da função. Caso a agente se mude para outro bairro, por exemplo, ela perde o cargo. Considerando que Cidade Tiradentes e Itaquera são regiões bastante populosas e de baixa renda, periferia de São Paulo, a ocupação de agente funciona como garantia de emprego e salário seguros.

A perspectiva dessa ocupação como saída para uma vida de poucas opções profissionais se mostrou aplicável também aos homens negros, ainda que eles sejam minoria em relação às mulheres. Na população masculina, o trabalho de agentes funciona como uma forma de ascensão social e, mais que isso, como forma de proteção contra a violência do Estado, uma vez que, por conta de todo um estereótipo social, são eles os mais sujeitos à violência policial e ao assédio do mercado do crime. Vale relembrar que, no caso das agentes mulheres, a cor também evidencia as condições de subalternidade social dessas trabalhadoras e que a maior parte delas é negra ou parda.

Na primeira parte do livro, "A emergência das "novas" políticas sociais brasileiras no contexto internacional, nacional e local", as autoras iniciam a discussão sobre o que sejam (ou como se formaram) as políticas públicas no Ocidente, suas matrizes históricas conceituais como, por exemplo, as diferenças entre proteção social e desenvolvimento social, entre filantropia e caridade, como a instituição "família" tornou-se a chave que pauta os objetivos das intervenções governamentais até chegar ao seu caráter central nas políticas públicas brasileiras, o que é denominado "familismo".

Fundamentando as bases epistemológicas da perspectiva familista nas teorias feministas que postulam a centralidade da divisão sexual do trabalho no desenho social, através da atribuição de papéis sociais e de gênero, demonstra-se como, historicamente, o papel de "cuidadora" do lar e das pessoas que nele habitam atribuiu às mulheres o lugar cativo de "mães" e, mais além e derivando disso, o de responsáveis pela ordem, pela correção moral, pelo dinheiro, pela gestão das contas. No extramuros dos lares também têm cabido às mulheres das comunidades as "reclamações" dos serviços públicos mais diretamente ligados ao cuidar, como os pleitos por postos de saúde, iluminação nas ruas, creches, etc. Juntando esse lugar social a algumas perspectivas religiosas, de cuidado e assistência social, temos uma espécie de "papel feminino ideal”, que se torna hegemônico.

É a partir desse papel feminino tradicional que as políticas públicas estruturam o familismo. Assim, as mulheres populares, ainda que não estejam envolvidas nos planejamentos políticos hierarquicamente superiores, têm tido papel central, sendo entendidas até hoje, especialmente nos países mais conservadores, como o sujeito-chave para o desenvolvimento de uma relação entre o Estado, seus programas sociais e população necessitada. Intercambiando o papel de gênero tradicional 
feminino e a ideia de família, essa última figura como a unidade social que serve de porta de entrada para as ações mais conservadoras de combate governamental à pobreza ou a alguns de seus efeitos. Nas palavras de uma das autoras:

[...] os campos de proteção social e do desenvolvimento têm tratado as categorias pobreza, Estado, mercado, família e gênero de modo entrelaçado, tomando-as como referência uma da outra, tanto no tempo como no espaço... (GEORGES; SANTOS, 2016, p. 69)

Nesse sentido vêm operando iniciativas como o PSF e o programa Bolsa Família, por exemplo, cuja preferência para a titularidade do benefício foi deliberadamente afirmada para as mulheres. Mas o que a obra nos relembra é que essa "preferência” das políticas públicas pelas mulheres sempre está ligada às "mulheres mães" e a um modelo tradicional e heteronormativo de família. Inclusive, na obra fica ressaltado que mulheres que diferem disso (mães entendidas como relapsas, desorganizadas ou que abandonam seus filhos) são objeto de "correção moral” por parte das outras mulheres ACS ou de algumas instituições controladoras, como as igrejas, por exemplo. Daí se depreender que esse papel central feminino não necessariamente aponta uma perspectiva "nova" que objetiva a autonomia das mulheres e substitui perspectivas patriarcais, mas, ao contrário, essa centralidade reafirma o papel feminino tradicional.

Em vários pontos diferentes do livro, observa-se como esse papel tradicional é percebido até como oportunidade de vida pelas próprias mulheres; como as entrevistadas reproduziram as ideias de casamento e formação de família como saída para situações de opressão ou vulnerabilidade: casar-se como estratégia para dividir as contas ou somar os salários e obter autonomia.

Um ponto nevrálgico das políticas públicas que é abordado sem medo na obra é a questão da mercantilização da pobreza e de como ela se liga não apenas com as instituições governamentais, mas também às prestadoras que terceirizam serviços básicos (principalmente de saúde e educação), os quais seriam, a princípio, função do Estado. Ressaltando a importância de organizações não governamentais (ONGs), Organização da Sociedade Civil de Interesse Público (Oscip), sindicatos, igrejas, etc. no funcionamento das políticas públicas, o texto nem cai num enaltecimento militante e nem numa demonização dessas instituições. Essa gama de organizações pode funcionar bem ou mal, por interesse ou ideologia, atendendo a grupos seletos ou a todos, mas o que se mostra inegável é que seus jogos políticos se desenvolvem dentro das comunidades de maneira muito forte, estando diretamente conectados com o funcionamento das políticas públicas: 
[...] independentemente de orientação política e partidária, parece desenhar-se uma conformação desse setor como um mercado onde se trocam "mercadorias políticas" (MISSE, 1997), isto é, onde a pobreza vira negócio e adquire um valor de troca (na maioria dos casos, em troca de influência da base eleitoreira). As entidades inserem-se nesse mercado da pobreza para ter acesso aos convênios com a prefeitura (através dos editais públicos), mas igualmente para obter o apoio de uma grande diversidade de atores... (GEORGES; SANTOS, 2016, p. 189-190)

Enfim, como ilustrado nesse trecho, o livro, através de uma perspectiva crítica e interseccional, nos dá um panorama bastante realista da população que forma os usuários e trabalhadores das políticas públicas analisadas, além dos meandros políticos de seu funcionamento. Figura como leitura fundamental para quem tem interesse nesse campo e busca uma análise extensiva cuja objetividade é enriquecida pela perspectiva antropológica não ingênua.

\section{REFERÊNCIAS}

GEORGES, Isabel; SANTOS, Yumi Garcia dos. As novas políticas públicas sociais na saúde e na assistência: produção local do serviço e relações de gênero. Belo Horizonte: Fino Traço, 2016. 